Saudi Journal of Biomedical Research

Abbreviated Key Title: Saudi J Biomed Res ISSN 2518-3214 (Print) |ISSN 2518-3222 (Online)

\title{
Seroprevalence of Antibodies to Cytomegalovirus, Rubella Virus and $T$. gondii among aborted women in El-Beida City
}

\author{
Marfoua S. Ali ${ }^{*}$, Salema R.M Qowaider ${ }^{2}$, Nagla. Y. Bait Almal ${ }^{1}$, Fayourz. A. Kahald ${ }^{3}$ \\ ${ }^{1}$ Zoology Department, Faculty of Science, Omar El-Mokhtar University, El-Beida -Libya \\ ${ }^{2}$ Microbiology and Immunology Department, Faculty of Medicine, Omar El-Mokhtar University, El-Beida -Libya \\ ${ }^{3}$ Chemistry Department, Faculty of Science, Omar El-Mokhtar University, El-Beida -Libya
}

DOI: $10.36348 /$ sjbr.2020.v05i12.003

| Received: 18.11.2020 | Accepted: 01.12.2020 | Published: 16.12.2020

*Corresponding author: Marfoua S. Ali

\section{Abstract}

This work was carried out to investigate the seroprevalence of antibodies to Cytomegalovirus, Rubella virus and $T$. gondii among aborted women in the 9 consecutive months (July 2018 to March 2019) at El-Beida City. A total of 95 women was tested using ELISA method for presence of $T$. gondii, Rubella and Cytomegalovirus (CMV) antibodies (IgG and $\operatorname{IgM}$ ) by commercial kit. Data from samples of serum found that, the sero-prevalence of T. gondii (IgG/ IgM) were the highest followed by Rubella (IgG/ IgM) and then CMV (IgG/ IgM). $67.74 \%$ of total women was get two type of antibodies against two different parasites. $22.6 \%$ were sero-positive for IgG anti-T. gondii and anti-CMV, $18.3 \%$ seropositive for IgG anti-T. gondii and anti-Rubella and $26.9 \%$ were sero- positive for IgG anti-CMV and anti-Rubella at same time. The highest prevalence was noted in age group 21-25 years followed with age groups 31-35 and 26-30. The rate of one miscarriage in abortive women was $50.6 \%$ higher than two and three miscarriages $29.9 \%$ and $11.5 \%$ respectively. Results were might give a better understanding about Rubella, $T$. gondii, and cytomegalovirus infections during pregnancy that cause the foetal loss.

Keywords: Seroprevalence, Antibodies Cytomegalovirus, Rubella Virus, T. gondii and El-Beida City.

Copyright () 2020 The Author(s): This is an open-access article distributed under the terms of the Creative Commons Attribution 4.0 International License (CC BY-NC 4.0) which permits unrestricted use, distribution, and reproduction in any medium for non-commercial use provided the original author and source are credited.

\section{INTRODUCTION}

Abortion is an issue in pregnancy wastage with its concomitant social and economic [1]. Pregnancy loss has been attributed to several factors involved in human reproduction. Genetic and uterine abnormalities, endocrine and immunological dysfunctions, infectious agents, environmental pollutants, psychogenetic factors and endometriosis are most important causes of spontaneous abortion [1]. Infections caused by $T$. gondii. gondii (T.gondii), Rubella virus and Cytomegalovirus (CMV) are major causes of pregnancy lose in human. Women affected with any of these diseases during pregnancy are at high risk for miscarriage, stillbirth, or for a child with serious birth defects and/or illness [2, 1].

Among apicomplexan, T. gondii is unique as it is probably the most successful parasite with its widespread distribution worldwide causing one of the most common parasitic infection, called toxoplasmosis. Remarkably, T. gondii's host range is exceptionally broad since it can infect virtually all nucleated cells of all warm-blooded animals including birds, marsupials, and mammals [3].

Rubella is caused by RNA virus of paramyxovirus group. It, also called German measles, is a viral infection that can easily be passed from person to person through sneezing or coughing. Rubella is less common today because a vaccine protects against it. But pregnant women with rubella can pass the virus to a fetus, which may be a serious condition [4]. Approximately $30 \%-50 \%$ fetuses of women who contact with Rubella during the first 3 months of pregnancy will be adversely affected by the virus. The Rubella virus readily invades the placenta and fetus during gestation [5]. A woman in the first 2 or 3 months of pregnancy who is exposed may develop the infection and give birth to child with serious congenital defects such as deafness and blindness [6].

CMV is a member of the family Herpesviridae. It is a public health problem which can be a potential killer or lifelong silent companion. Morphologically is very similar to other herpes viruses [7]. Acute infection usually occurs in 
immunosuppressed and AIDS patients, and the symptoms vary from mild to severe. The severity of infection depend on a number of factors, such as the age of host, his immune status and the stage of pregnancy at the time of acquiring the infection ("congenital") [8]. CMV infection in pregnancy is extremely serious and considered a major health issue in several parts of the world which requires precautionary measures. Congenital infections are acquired when the developing fetus becomes infected by CMV crossing the placental tissues from a mother who acquired a primary CMV infection during the pregnancy. Some of these congenitally infected infants are born with severe deformities and die shortly after birth. CMV is among the leading congenital causative agents in developed countries [4]. Furthermore, the immunity of the mother does not provide protection against congenital infection but it reduces the severity of symptoms during acute infection [4]. Fetal damage is more likely to be severe when maternal infection occurs early in pregnancy [9].

Wide array of organisms, like TORCH agents, Chlamydia trachomatis, Niesseria gonorrhoeae and others can cause recurrent pregnancy wastage due to maternal infections during pregnancy [10]. Perinatal infections account for $2 \%$ to $3 \%$ of all congenital anomalies. TORCH, which includes Toxoplasmosis, other (syphilis, varicella-zoster, parvovirus B19), Rubella, CMV, and Herpes infections, are of the most common infections associated with unfavorable outcome of pregnancy [11]. Primary infection with any of the TORCH agents during pregnancy can lead to adverse outcomes, which are initially inapparent or asymptomatic and thus difficult to diagnose on clinical grounds [12]. The ultimate consequences of intrauterine infection can be any one of the following [11]: no significant problem, asymptomatic chronic infection, spontaneous abortion, intrauterine fetal death, stillbirth or neonatal death, fetal malformation or neonatal infection. This study was aimed to find out seroprevalence of $T$. gondii, CMV, rubella and herpes virus infections in a group of abortion women in ElBaida City, Libya.

\section{MATERIALS AND METHODS}

Ninety five abortive women who attended to different private clinics for consultation and investigations during the period between July and September 2018 were taken as a study group. Topic of prevalence antibodies for acute and chronic infection for more causes of abortion spreading that is including T. gondii, CMV and Rubella virus. All sera samples of 95 abortive women were analyzed by using TORCH panel Rapid Test to measure the titer of immunoglobulin $\mathrm{G}(\mathrm{IgG})$ and immunoglobulin $\mathrm{M}$ (IgM) against previous parasites.
The onsite TORCH panel Rapid Test is a lateral flow chromatographic immunoassay for the qualitative detection and differentiation of antibodies (IgG and IgM) to T. gondii, Rubella virus, CMV, (Herpes simplex virus1 (HSV-1) and herpes simplex virus2 (HSV-2). The onsite TORCH panel rabid test detects and differentiates $\operatorname{IgG}$ and $\operatorname{IgM}$ antibodies for all 5 TORCH infections. In general, a negative test result indicates that the individual is at risk for acquiring a primary infection. All the samples were firstly tested for the TORCH infections by using sandwich and capture ELISA based commercial kits (Biotech Lab. Ltd, UK and Omega Diagnostics, UK) and the BioTek ELx50 biochemistry analyzer (Winooski, Vermont, U.S.A) in the Serology Section of the Department of Microbiology. All the sera were assayed according to the manufacturer's instructions and the results were calculated on the basis of the cut off Activity Index (AI). The values which were $10 \%$ above the AI were considered as positive, whereas those which were $10 \%$ below the AI were taken as negative. The values which were in between these values were considered as equivocal. A 95\% confidence interval was calculated for the positive cases in each of the TORCH components.

\section{RESULTS}

Total of 95 cases was tested for presence of antibodies (IgG and IgM) against T. gondii, Rubella, CMV and Herpes. The seroprevalence of $T$. gondii IgG was the highest followed by Rubella $\operatorname{IgG}$ and then CMV IgG, From total 95 sample of serum, $49.5 \%$ were found to be seropositive for T. gondii, $\operatorname{IgG}, 15.9 \%$ seropositive for $T$. gondii, $\operatorname{IgM}$ and $34.7 \%$ were negative. $42.1 \%$ were found to be seropositive for CMV, IgG, $16.8 \%$ seropositive for CMV, IgM and $41.1 \%$ were negative. In case of Rubella, $44.2 \%$ were found to be seropositive for Rubella, $\mathrm{IgG}, 18.9 \%$ seropositive for Rubella, IgM and $36.8 \%$ were negative, as shown in (Figure-1). Herpes antibodies were not recorded. And also compare them with those who have couple antibodies against two different parasites was $33.3 \%$. was found to have IgG anti-T. gondii and antiCMV , 27\% found to have IgG anti-T. gondii and antiRubella and $39.7 \%$ found to have IgG anti-CMV and anti-Rubella at same time (Figure-2).

In term of distribution of positive cases of $T$. gondii, Rubella and CMV antibodies at different age groups showed the most prevalence was at 20-30 age group followed by 31-40 age group and then 41-50 as shown in Table-1. All subjects (95) were subdivided into three groups according to number of miscarriages (1, 2 and more than 3 miscarriages) as shown in Table2. The rate of one miscarriage in abortive women was higher than two and three miscarriages. 


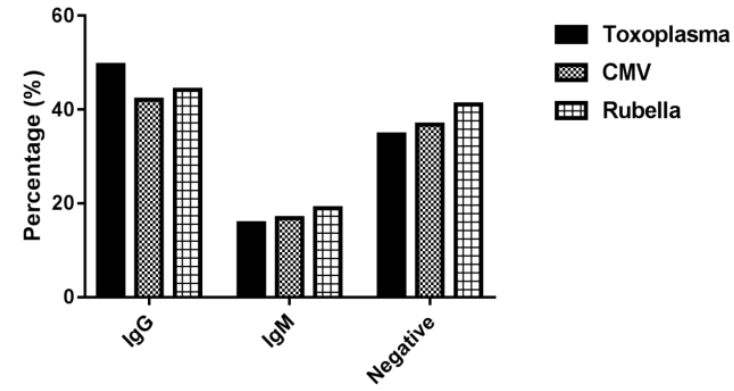

Fig-1: Percentage incidence of $T$. gondii, Rubella and CMV antibodies in miscarriage women.

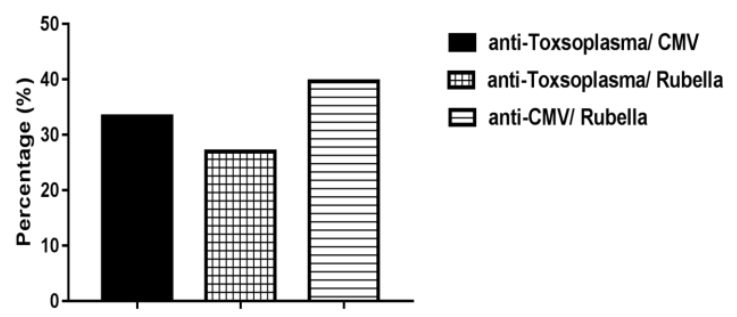

Fig-2: Percentage levels of antibodies (IgG and IgM) against couple parasites at same time ( $T$. gondii, $C M V$ and Rubella) in miscarriage women

Table-1: Distribution between prevalence of $T$. gondii, Rubella and CMV antibodies at different age groups

\begin{tabular}{|l|l|l|l|}
\hline & \multicolumn{3}{|l|}{ No of cases } \\
\hline & $\mathbf{2 0 - 3 0}$ & $\mathbf{3 1 - 4 0}$ & $\mathbf{4 1 - 5 0}$ \\
\hline All subjects & 42 & 32 & 21 \\
\hline Positive- T. gondii & 20 & 12 & 8 \\
\hline Positive CMV & 10 & 10 & 6 \\
\hline Positive Rubella & 12 & 10 & 7 \\
\hline Positive for two or more & 30 & 19 & 15 \\
\hline
\end{tabular}

Table-2: Number of miscarriage in all 95 subjects

\begin{tabular}{|l|l|}
\hline Number of miscarriages & No of cases (\%) \\
\hline One & $46(48.4)$ \\
\hline Two & $28(29.5)$ \\
\hline Three & $12(12.6)$ \\
\hline More than three & $9(9.4)$ \\
\hline
\end{tabular}

\section{DISCUSSION}

Rubella, T. gondii and CMV agents are known to cause infections in utero and are often responsible for pregnancy lose, but there are considerable geographical variations in the prevalence of these agents among the women of child bearing age and are responsible for pregnancy wastage [5]. Topic of prevalence antibodies for acute and chronic infection for more causes of abortion spreading that is including $T$. gondii, CMV and Rubella virus [13]. Therefore, a total of 95 cases were tested for presence of $T$. gondii, Rubella and CMV antibodies (IgG and IgM). In current study was found that the prevalence of $T$. gondii (IgG/ $\mathrm{IgM}$ ) were the highest followed by Rubella (IgG/ IgM) and then CMV (IgG/ IgM). These results were in concordance with the findings of a comparable study from India [14].
Previous study in Turkey, also reported overall anti- $T$. gondii, anti-Rubella, and anti-CMV IgM and IgG antibody positivity rates were $1.1 \%, 0.5 \%$ and $2.6 \%$, and $37.6 \%, 86.5 \%$ and $100 \%$, respectively [15]. Another study in El-Beida City also reported that prevalence of IgG against Rubella infection (98.59\%), IgG CMV (96.36\%), IgG T. gondii (39.39\%), antiRubella IgM and anti-CMV IgM antibodies were $(0 \%)$ and $(2.8 \%)$ respectively [16].

Most of the previous studies in Libya have concentrated on the prevalence of $T$. gondii infection among pregnant women. These studies appear to be in accordance with the high prevalence rates of $T$. gondii infection which reported by most of the previous studies in Arab countries for example in Saudi Arabia [16, 17], in Tunisia [19, 20]. In Libya, many studies done to detect the prevalence of $T$. gondii antibodies and show high prevalence rates in their studies [21-26]. However, the main reasons for this pattern of high prevalence rate of $T$. gondii infection in Libya needs more studies particularly in Northeast of Libya.

In this study the comparison between subjects who have couple antibodies against two different parasites was $67.74 \%$. The highest prevalence was found in subjects who have IgG anti-T. gondii and antiCMV, followed by found IgG anti- $T$. gondii and antiRubella then in subjects who have IgG anti-CMV and anti-Rubella at same time. These results revealed to another study repeated that the prevalence anti-Rubella IgG and anti-CMV IgG antibodies were found in high percentage [16]. The detection of IgG indicated that the pregnant women had previously been infected with Rubella, T. gondii and/or CMV viruses. After the infection, IgG remains in the body for life and protects considerably against the next infections. There are many studies about the association between CMV infection and pregnancy loss; these studies showed that CMV can result in abortion or stillbirth [27, 28].

In term of age, the cases per age groups were corrected according to demographic data, this study found that age group from 21 to 40 years were highest prevalence for presences of infection and this is pointing to rate of fertility among this age group. This result was not agree with that of Al-Harthi et al., [29] who reported the highest rate of sero-conversion among pregnant women aged 35-45 years. However, it is consistent with the age-group of pregnant women (1535 years) that Jackson and Hutchison [30] reported to have the highest rate of sero-conversion, and also agrees with the data collected from Libya [31, 32]. Relation between an increases in the prevalence of chronic infection with middle age, indicate that exposure to (oocyst-contaminated) soil, which tends to be greatest during childhood, may not be the principal mechanism by which girls and women acquire $T$. gondii [33]. This high rate of sero-prevalence in 21-35 age group may also belong to higher contact with cats or 
infected things and vegetables than other age groups [34]. This finding relatively also was analogous with study in Iran [35] and in Iraq [36].

Result from number of miscarriages was found that over all subjects the rate of one miscarriage in abortive women was higher than two and three miscarriages. The current study agreed with studies where they found the highest rate of infection among women who have suffered single abortion $[37,36]$. On other hand the current study did not agree with [38]. The reason for the high incidence among aborted women may return to the type of acute injury or reactivate chronic injury due to decrease immunity of pregnant mother's body as the time of the injury during pregnancy has an important role to determine the fate of the fetus [37, 36].

The serological tests are useful for the diagnosis of Rubella, T. gondii and CMV agents through the detection of antibodies in the serum samples and determine the stage of infection that were in the acute phase or chronic [39].

The presence of the Rubella IgG antibodies were found in around $42 \%$ of the pregnant women, which was in concordance with the findings of a comparable study in India [14]. Sero-epidemiological studies have shown that risk of the congenital Rubella infection following a maternal infection ranged from $5 \%$ to $50 \%$ in various studies, with an increasing severity when it was acquired in the first trimester of the pregnancy $[10,1]$. Moreover, there is a considerable variation in the prevalence of the Rubella specific IgG antibodies among the women of the child bearing ages, with studies suggesting a prevalence of a $39 \%$ Rubella immunity, thus leaving about $61 \%$ of the women susceptible to the Rubella infection [40].

CMV infection in pregnancy has a higher incidence of symptomatic congenital infection and foetal loss [12]. Seroprevalance of CMV IgG observed in current study is agree with some other studies in different other countries in same regions include, Egypt [41], Nigeria [42], Iran [43] and Saudi Arabia [44]. Though more women who are in the child bearing ages are already seropositive, reinfection with a new strain of CMV can cause infections even in the presence of detectable IgG levels [45, 40]. This study showed a seropositive rate for the CMV specific IgM, thus indicating a higher prevalence in and around Varanasi. Therefore, it is necessary that behavioural and educational interventions for prevention are given and that an antenatal screening is routinely done.

It has already been emphasized that knowing the epidemiology of the TORCH infections is an important aspect in the development of strategies for the prevention of congenital infections. Hence, it should be recommended that all the antenatal cases should be routinely screened for the TORCH complex to avoid adverse foetal outcomes. Moreover, similar studies as this one, which document the seroprevalence of the TORCH infections, should be done to create a baseline data in the country. In such a context, the development of a vaccine strategy against these infections, especially in the developing countries, should be considered.

\section{REFERENCES}

1. Tiwari, S., Arora, B. S., \& Diwan, R. (2016). TORCH IgM seroprevalence in women with abortions as adverse reproductive outcome in current pregnancy. International Journal of Research in Medical Sciences, 4, 784-788.

2. Simgamsetty, S., Yarlagadda, P., Yenigalla, B. M., \& Myneni, R. B. (2015). Study of seroprevalance of Toxoplasma gondii, Rubella virus and Cytomegalovirus (ToRC) infections in antenatal women presented with bad obstetric history and comparative evaluation of Nanoplex ToRCH screen ELISA kit with VIDAS. International Journal of Research in Medical Sciences, 3, 1203-1208.

3. Dubey, J. (2009). History of the discovery of the life cycle of Toxoplasma gondii. International journal for parasitology, 39, 877-882.

4. Singla, N., Jindal, N., \& Aggarwal, A. (2004). The seroepidemiology of rubella in Amritsar (Punjab). Indian journal of medical microbiology, 22, 61 .

5. Coulter, C., Wood, R., \& Robson, J. (1999). Rubella infection in pregnancy. Communicable diseases intelligence, 23, 93-96.

6. Deorari, A., Broor, S., Maitreyi, R., Agarwal, D., Kumar, H., Paul, V., \& Singh, M. (2000). Incidence, clinical spectrum, and outcome of intrauterine infections in neonates. Journal of tropical pediatrics, 46, 155-160.

7. Li, Z., Yan, C., Liu, P., Yan, R., \& Feng, Z. (2009). Prevalence of serum antibodies to TORCH among women before pregnancy or in the early period of pregnancy in Beijing. Clinica chimica acta, 403, 212-215.

8. Stagno, S., Pass, R. F., Dworsky, M. E., Henderson, R. E., Moore, E. G., Walton, P. D., \& Alford, C. A. (1982). Congenital cytomegalovirus infection: the relative importance of primary and recurrent maternal infection. New England Journal of Medicine, 306, 945-949.

9. Boppana, S. B., Pass, R. F., \& Britt, W. J. (1993). Virus-specific antibody responses in mothers and their newborn infants with asymptomatic congenital cytomegalovirus infections. Journal of Infectious Diseases, 167, 72-77.

10. Thapliyal, N., Shukla, P., Kumar, B., Upadhyay, S., \& Jain, G. (2005). TORCH infection in women with bad obstetric history--a pilot study in Kumaon region. Indian journal of pathology \& microbiology, 48, 551.

11. Johnson, P. M., Barnes, R., Hart, C. A., \& Francis, W. (1984). Determinants of immunological 
responsiveness in recurrent spontaneous abortion. Transplantation, 38, 280-284.

12. Turbadkar, D., Mathur, M., \& Rele, M. (2003). Seroprevalence of torch infection in bad obstetric history. Indian journal of medical microbiology, $21,108$.

13. Gomella, T. (1994). Infectious Diseases: TORCH Infections. Neonatology: Management, Procedures, On-Call Problems, Diseases and Drugs, Norwalk, CT: Appleton \& Lange.

14. Sen, M., Shukla, B., \& Tuhina, B. (2012). Prevalence of serum antibodies to TORCH infection in and around Varanasi, Northern India. Journal of clinical and diagnostic research: JCDR, 6, 1483_1485.

15. Parlak, M., Çim, N., Erdin, B. N., Güven, A., Bayram, Y., \& Yildızhan, R. (2015). Seroprevalence of Toxoplasma, Rubella, and Cytomegalovirus among pregnant women in Van. Turkish journal of obstetrics and gynecology, 12, 79-82.

16. Saad, K. A. O., \& Yousef, N. (2016). Evaluation of Rubella, Toxoplasma gondii, and cytomegalovirus seroprevalences in women with miscarriage as adverse reproductive outcome in current pregnancy in ALBIYDA /LIBYA IOSR Journal of Pharmacy and Biological Sciences (IOSR-JPBS) 11, 81-84.

17. Al-Mohammad, H., Amin, T., Balaha, M., \& AlMoghannum, M. (2010). Toxoplasmosis among the pregnant women attending a Saudi maternity hospital: seroprevalence and possible risk factors. Annals of Tropical Medicine \& Parasitology, 104, 493-504.

18. BIN DAJEM, S. \& ALMUSHAIT, M. 2012. Detection of Toxoplasma gondii DNA by PCR in blood samples collected from pregnant Saudi women from the Aseer region, Saudi Arabia. Annals of Saudi medicine, 32, 507-512.

19. Bouratbine, A., Siala, E., Chahed, M., Aoun, K., \& Ben, R. I. (2001). Sero-epidemiologic profile of toxoplasmosis in northern Tunisia. Parasite (Paris, France), 8, 61-66.

20. Fakhfakh, N., Kallel, K., Ennigro, S., Kaouech, E., Belhadj, S., \& Chaker, E. (2013). Risk factors for Toxoplasma gondii and immune status of pregnant women: cause and effect? La tunisie Medicale, 91, 188-190.

21. Alkateb, A., Flamer, O., Bellasher, A., Shakshok, G., Albellazy, M., \& Abudher, A. (2007). Role of the meat in transmittion of toxoplasmosis. Infectious and endemic disease. . Scientific conference (IEDSC), Tripoli, Libya, 83.

22. Alzaidy, J. (2007). Serological epidemiological study of toxoplasmosis in women in some areas of the Green Mountain M,Sc, Thesis, University of Omar Almukhtar.

23. Kassem, H., \& Morsy, T. (1991). The prevalence of anti-Toxoplasma antibodies among pregnant women in Benghazi,(SPLAJ) Libya. Journal of the Egyptian Society of Parasitology, 21, 69-74.

24. Khader, M., \& El Nageh, M. (1987). Serological Survey for Toxoplasmosis in Tripoli Socialist People's Libyan Arab Jamahiriya (Libya). Transactions of the Royal Society of Tropical Medicine and Hygiene, 81, 761-763.

25. Legnain, M., Singh, R., \& Prawecka, M. (1992). Prevalence of Toxoplasma antibodies and pregnancy wastage among women in Benghazi with pertinent review of literature. Garyounis Medical Journal. , 6, 69-77.

26. Magrhi, S., Abudher, A., Guma, N., Hagrasi, H., Mohammed, S., Musbah, M., Ali, M., \& Abeed, S. (2003). Toxoplasmosis and Pregnancy outcome, Second national Biotechnology. Conference proceeding Book, 435-42.

27. Fairley, J., Baillie, J., Bain, M., \& Sinclair, J. (2002). Human cytomegalovirus infection inhibits epidermal growth factor (EGF) signalling by targeting EGF receptors. Journal of General Virology, 83, 2803-2810.

28. Nahum, A., Dadi, H., Bates, A., \& Roifman, C. M. (2012). The biological significance of TLR3 variant, L412F, in conferring susceptibility to cutaneous candidiasis, CMV and autoimmunity. Autoimmunity reviews, 11, 341-347.

29. Al-Harthi, S. A., Jamjoom, M. B., \& Ghazi, H. O. (2006). Seroprevalence of Toxoplasma gondii among pregnant women in Makkah, Saudi Arabia. Umm Al-Qura University, Journal of ScienceMedcine- Engnerring, 18, 217-227.

30. Jackson, M., \& Hutchison, W. (1989). The prevalence and source of Toxoplasma infection in the environment. Advances in parasitology. Elsevier.

31. Elsaid, M., Azbedah, A., Dia Eddin, E., \& Alkout, A. (2014). The prevalence of Toxoplasma gondii infection in psychiatric patients in Tripoli, Libya. Journal of American Science, 10.

32. Gashout, A., Amro, A., Erhuma, M., Al-Dwibe, H., Elmaihub, E., Babba, H., Nattah, N., \& Abudher, A. (2016). Molecular diagnosis of Toxoplasma gondii infection in Libya. BMC infectious diseases, 16, 157.

33. Jenum, P. A., Stray-Pedersen, B., Melby, K. K., Kapperud, G., Whitelaw, A., Eskild, A., \& Eng, J. (1998). Incidence of Toxoplasma gondii infection in 35,940 pregnant women in Norway and pregnancy outcome for infected women. Journal of Clinical of Microbiology, 36, 2900-2906.

34. Bobić, B., Jevremović, I., Marinković, J., Šibalić, D., \& Djurković-Djaković, O. (1998). Risk factors for Toxoplasma infection in a reproductive age female population in the area of Belgrade, Yugoslavia. European journal of epidemiology, 14, 605-610.

35. Fallahi, S., Badparva, E., Mohammadi, M., \& Ebrahimzadeh, F. (2009). Seroepidemiological study of Toxoplasmosis gondiiin women referred 
to Khorramabad laboratory of health center for medical examination before marriage, Lorestan province, Iran, 2008. Asian journal of biological sciences, 2(3):88-94.

36. Hadi, H. S., Kadhim, R. A., \& Al-Mammori, R. T. (2016). Seroepidemiological aspects for Toxoplasma gondii infection in women of Qadisiyah province, Iraq. International Journal of PharmTech Research, 9, 252-259.

37. Al-Khashab, F. M. B. (2009). Isolate, diagnose the parasite Toxoplasma gondii and the study of its effects pathological and immunological. PhD. Ph.D. thesis.

38. Aladlan, A. A. J. (2007). Serological and diagnostic study of the parasite Toxoplasma gondii in aborted women by using PCR technology in Thi-Qar province. M.Sc, Thesis, Thi-Qar University.

39. Robert-Gangneux, F., \& Dardé, M. L. (2012). Epidemiology of and diagnostic strategies for toxoplasmosis. Clinical microbiology reviews, 25, 264-296.

40. Mousa, D., Mohammad, M., \& Toboli, A. (2011). Toxoplasma gondii infection in pregnant women with previous adverse pregnancy outcome. Medical Journal of Islamic World Academy of Sciences, 109, 1-8.
41. El-Nawawy, A., Soliman, A. T., El Azzouni, O., Amer, E. S., Karim, M. A., Demian, S., \& El Sayed, M. (1996). Maternal and neonatal prevalence of toxoplasma and cytomegalovirus (CMV) antibodies and hepatitis-B antigens in an Egyptian rural area. Journal of tropical pediatrics, 42, 154-157.

42. Akinbami, A. A., Rabiu, K. A., Adewunmi, A. A., Wright, K. O., Dosunmu, A. O., Adeyemo, T. A., Adediran, A., \& Osunkalu, V. O. (2011). Seroprevalence of cytomegalovirus antibodies amongst normal pregnant women in Nigeria. International journal of women's health, 3, 423428.

43. Doroudchi, M., Dehaghani Samsami, A., Emad, K., \& Ghaderi, A. (2001). Seroepidemiological survey of rubella immunity among three populations in Shiraz, Islamic Republic of Iran. 7, 128-138.

44. Hossain, A. (1989). Seroepidemiology of rubella in Saudi Arabia. Journal of tropical pediatrics, 35, 169-170.

45. Alsamarai, A. M., Khalil, Z., \& Aljumaili, M. (2013). Seroepidemiology of Toxoplasma, Rubella, Cytomegalovirus and Herpes Simplex Virus-2 in women with bad obstetric history. PART I: Toxoplasma and Rubella infections. Our Dermatology Online, 4, 522-535. 